\title{
A IMPORTÂNCIA DO TRABALHO DO PSICÓLOGO NO AMBIENTE ESCOLAR: PERSPECTIVAS DA EDUCAÇÃO NA ATUALIDADE
}

DOI: $10.22289 / 2446-922 X . V 2 E E A 2$

\author{
Ivana Gomes Moreira² \\ Renata Ferreira dos Santos Oliveira
}

\section{RESUMO}

O presente trabalho objetivou analisar a importância da atuação do psicólogo na solução dos problemas de aprendizagem com origem em distúrbios psicológicos e identificar práticas que funcionem neste sentido. Justificam a escolha do tema a sua atualidade, a relevância científica, social e acadêmica: trata-se de tema atual, visto que um dos maiores desafios da educação e dos educadores é lidar com as questões de ordem psicológica com reflexo na aprendizagem. Apresenta a pesquisa relevância científica, pois as conclusões dela decorrentes poderão servir de base para estudos mais criteriosos sobre a atuação do psicólogo na escola. É também relevante do ponto de vista social e acadêmico porque interessa à sociedade a busca pela solução de problemas que dificultam a aprendizagem escolar, sendo que a pesquisadora, enquanto estudante do Curso de Psicologia da Faculdade Patos de Minas - FPM utiliza-se da pesquisa para consolidar e aprimorar conceitos e conhecimentos adquiridos na trajetória acadêmica. A metodologia utilizada consiste na leitura, análise e interpretação de textos de autores nacionais que, na atualidade, dedicam-se ao estudo da relação entre a Psicologia e a Educação. A conclusão apresenta três vertentes: a) as razões do fracasso escolar não repousam apenas na escola e na relação professor/aluno. Muitas vezes o sucesso na aprendizagem depende da solução de problemas psicológicos, o que requer a intervenção de um profissional da psicologia; b) a atuação do psicólogo na escola não pode estar restrita ao atendimento do aluno e da família, a orientação ao profissional da educação (professor, orientador, supervisor) é fundamental para a superação dos entraves psicológicos da aprendizagem; c) o psicólogo na escola deve atuar não apenas de modo curativo, mas principalmente com enfoque preventivo.

Palavras Chave: Psicologia; Aprendizagem; Escola.

\begin{abstract}
The present course conclusion research aims to investigate the importance of the psychologist work on the solution of learning problems that come from psychological disorder and reach actions that work in this sense. The choice of the subject is justified by its opportunity, scientific, social and academic importance: It is a nowadays theme, so that one of the largest challenges of education and for educators is handing with psychological questions with reflections on learning. Presents the research a scientific importance, so its conclusions could serve as basis to most advanced studies about the work of the psychologist in school. It is also important from the social and academic view because it is weighty to society the research by solutions for problems that hamper the school learning, being the researcher, as a student in
\end{abstract}

2 Endereço eletrônico de contato: yvanagmoreira@yahoo.com.br

Outubro, 2016:2(Edição Especial):14-27. 
the Psychology Course in Faculdade Patos de Minas - FPM uses the research to solidify and improve concepts and knowledge's acquired in her academic trajectory. The methodology consists on reading, analysis and interpretation of texts by national authors that, nowadays, have dedicated to the study of the relation between education and psychology. The conclusion presents three slopes: a) the reasons of the scholar failure doesn't rest only on school and on teacher/student relation. Several times the triumph in learning depends on the solution of psychological problems, what claims the intervention of a psychology professional; b) the work of the psychologist in school can't be limited to student and family, so the orientation to education professional (teacher, advisor, supervisor) is essential to overcome the learning psychological obstacles; c) the psychologist in school must work not only on the curative but mainly on preventive approach.

Keywords: Psychology; Learning; School.

\section{INTRODUÇÃO}

Nos tempos atuais, em que a escola vem perdendo espaço no mundo exterior e em que a tecnologia da informação tende a substituir a sala de aula, é necessário que se pense que o ambiente escolar é o único ambiente de aprendizagem. Na prática, a escola é apenas um dos diversos locais em que o indivíduo se apropria do conhecimento e dos princípios fundamentais da cultura de seu grupo, embora continue ela sendo local privilegiado para que esta apropriação aconteça de modo mais sistematizado.

A escola, hoje, não é mais a principal detentora do saber. O papel do professor somente como transmissor do conhecimento não tem mais lugar nesse espaço. É mais importante indicar onde o aluno pode encontrar as informações de que necessita para a construção do seu saber como poderá transformá-las em conhecimento do que ser um repassador dos conteúdos de sua área. (1)

No momento em que se percebe que a escola está em transformação e que novos paradigmas e novos desafios impõem-se ao educador na atualidade, forçoso é reconhecer que somente o professor não dá mais conta de alavancar o processo ensino/aprendizagem: questões de ordem social, cultural, econômica e psicológica interferem diretamente neste processo, de modo que se faz necessária a atuação de uma equipe multiprofissional dentro da escola para que essa passe a ser mais eficiente e, de fato, configure-se como um local de apropriação do saber. Um profissional indispensável nesta equipe é o psicólogo, uma vez que grande parte dos entraves à aprendizagem na atualidade é de ordem psicológica.

O principal papel do psicólogo na escola é o de promover reflexões a respeito das práticas sociais e escolares que produzem os problemas de aprendizagem. Se perguntar quem é este sujeito escolar, de onde veio, como estudou, quais oportunidades teve, que professores passaram por sua história e como se deram estas relações, além de tentar despertar a reflexão dos vários fatores que interferem na produção da queixa escolar, 
procurando entender qual o local em que o aluno se insere na relação com a escola; possibilitar que o professor considere a importância da sua relação com o aluno na construção da sua subjetividade e remover obstáculos da aprendizagem, entendendo que problemas de aprendizagem devem ser entendidos no conjunto de relações institucionais, históricas, psicológicas e pedagógicas que constitui a escola.(2)

A atuação deste profissional no ambiente escolar não fica restrita ao trabalho com alunos. Na verdade, o psicólogo pode e deve estar atento à atuação docente e atuar junto ao professor para que esse compreenda a dimensão sociocultural do processo ensino/aprendizagem e passe a ver o aluno como um ser em transformação, sujeito a erros e acertos.

O psicólogo escolar deve criar condições para que os docentes repensem e problematizem suas práticas; ajudá-los na compreensão do importante papel que tem como agentes da história; auxiliar na compreensão crítica em relação ao psiquismo, desenvolvimento humano, e de suas articulações com a aprendizagem e as relações sociais. (3)

Entretanto, a atuação do psicólogo no contexto escolar não se restringe ao atendimento de alunos e professores para a solução de problemas de ordem psicológica com reflexo na aprendizagem: no que se refere ao planejamento das atividades pedagógicas e à elaboração de um projeto político pedagógico que considere os aspectos psicológicos que influem no processo de aprendizagem este profissional possui um campo promissor. Não é suficiente que o psicólogo atenda alunos e professores em consultas e entregue à escola um feedback recomendando as providências cabíveis. É necessário que ele acompanhe o processo antes (planejamento pedagógico), durante (análise e anamnese) e depois (acompanhamento).

O psicólogo escolar tenta solidificar sua atuação profissional a capacitar-se tecnicamente para atender as demandas peculiares da escola. Torna-se imprescindível, então, que ele adentre o universo dos mais variados diálogos da educação, bem como em temas específicos, a exemplo das adaptações curriculares, projetos pedagógicos e interdisciplinares, processos de aprendizagem, manejo e técnicas de grupo, dentre outras propostas de trabalho que visem a uma ressignificação de olhares sobre o aluno e à redução de rotulações e diagnósticos desprovidos de análises e observações convincentes. (4)

Evidentemente as razões do fracasso na aprendizagem não repousam apenas na questão individual, mas perpassa a dimensão cognitiva.

O fracasso no processo de aprendizagem sistemática é muito menos determinado por questões individuais do que por mecanismos institucionais e políticos. Não há como negar

Outubro, 2016:2(Edição Especial):14-27. 
a influência dos aspectos cognitivos e afetivos constituídos na criança, mas há que se considerar que as relações escolares podem contribuir, modificar ou reforçar quaisquer que sejam esses aspectos, criando e recriando inúmeras outras situações desafiadoras, aversivas ou violentas. (5)

A atuação do psicólogo na escola, por conseguinte, passa pela identificação e análise destes aspectos exteriores que interferem na aprendizagem.

O objetivo da pesquisa é verificar a importância da atuação do profissional da psicologia na escola junto aos alunos e professores, em todas as fases do processo ensino/aprendizagem: por meio da leitura e análise de textos de autores nacionais que explorem as possibilidades de atuação do psicólogo no campo educacional, dentro e fora das salas de aula.

A hipótese é a de que o trabalho do psicólogo no ambiente escolar possa contribuir para a redução dos índices de repetência e evasão, uma vez que atuando junto aos alunos, professores e famílias, o psicólogo contribui para a busca de soluções para as dificuldades de aprendizagem com origem nos desvios comportamentais e distúrbios psicológicos.

A presente pesquisa foi realizada com base em levantamento bibliográfico e tratamento de informações. Deste modo, o método consiste basicamente na seleção, análise e tratamento de informações retiradas de fontes bibliográficas e webliográficas atualizadas. $\mathrm{O}$ material a ser utilizado constitui-se de textos de autores nacionais publicados mais recentemente: artigos científicos sobre a atuação do Psicólogo na educação, notadamente aqueles que tratam especificamente da atuação do profissional dentro da escola, como textos jornalísticos, livros especializados, manuais de psicologia e textos diversos impressos ou virtuais de fontes confiáveis.

\section{AMBIENTE ESCOLAR}

Muito se tem discutido, especialmente após a publicação da Lei das Diretrizes e Bases da Educação Nacional (LDB - Lei 9394/96) (6), sobre as razões do fracasso escolar. Especialistas afirmam serem múltiplas as causas do fracasso e apontam fatores como família, despreparo do educador e desigualdade social como causas mais frequentes. Como causa imediata costuma ainda ser apresentada a falta de preparo do professor. Contudo, raras vezes o professor assume sua parte nessa responsabilidade, especialmente porque assumir seria autodeclarar sua incompetência no processo pedagógico. (7)

Outubro, 2016:2(Edição Especial):14-27. 
No que se refere especificamente à dimensão familiar, cada vez mais, percebe-se que os tempos mudaram, trazendo uma nova perspectiva em que a família não é mais centrada no patriarcalismo e a escola também deixou de ser o único espaço de aprendizagem.

As problemáticas atuais que envolvem a escola são, em grande medida, oriundas das transformações que a sociedade contemporânea vivencia; nesse sentido, estas transformações, refletem-se nas diversas interações que ocorrem no contexto da escola, sobretudo no espaço da sala de aula, e têm tornado cada vez mais complexa a natureza das relações que se estabelecem no cotidiano escolar. (8)

Uma das causas mais frequentes, comumente apontadas como desencadeadoras do fracasso escolar, é a negligência da família em relação à vida escolar de seus filhos. Essa explicação, que se afirma no âmbito da psicologia clínica, atribui o fracasso escolar aos conflitos familiares geradores de perturbações de ordem afetiva. As dificuldades de aprendizagem são concebidas como consequências desses conflitos e manifestam-se preferencialmente em crianças oriundas de famílias problemáticas. A patologia relativa ao relacionamento dos membros da família é ainda mais acentuada quando a personalidade da criança é caracterizada por condutas agressivas, nervosismo e imaturidade. (5)

Embora o fracasso escolar não se restrinja à mensuração da aquisição dos conhecimentos mínimos em cada disciplina, em geral, tende-se a acreditar que ele se manifesta quando o aluno não consegue assimilar aquilo que se convencionou a chamar de saberes fundamentais. Geralmente o fracasso escolar se dá quando um aluno não consegue atingir as expectativas da escola e cumprir com as exigências escolares no sentido de aprender o que a escola e a sociedade valorizam como "saberes fundamentais e legítimos". (9)

Sendo assim, torna-se indispensável discutir os fatores que influenciam no fracasso e no sucesso escolar. Alguns destes fatores são intraescolares (pertencentes à organização da escola) e outros são extraescolares (pertencentes ao contexto ou à família dos alunos). A família está entre os fatores indicados por estudos como importantes para o desempenho dos alunos no sentido das formas de relação que são estabelecidas para com a escola e os professores pelas famílias. (10)

Não importa quão desestruturada seja uma família, ela será sempre o refúgio, um porto mais ou menos seguro para o qual a criança e o adolescente sempre correm nos momentos de maior aflição. Deste modo, ao psicólogo atuando no ambiente escolar, cabe também dimensionar o grau de importância que o aluno com problemas de aprendizagem atribui ao seu relacionamento familiar e como a família lida com os problemas do menor.

Outubro, 2016:2(Edição Especial):14-27. 
[...] a família é o espaço indispensável para a garantia da sobrevivência de desenvolvimento e da proteção integral dos filhos e demais membros, independentemente do arranjo familiar ou da forma como se vêm estruturando. É a família que propicia os aportes afetivos e, sobretudo, materiais necessários ao desenvolvimento e bem-estar dos seus componentes. Ela desempenha um papel decisivo na educação formal e informal, é em seu espaço que são absorvidos o valor ético e humanitário, e onde se aprofundam os laços de solidariedade. (11)

A responsabilidade solidária família/estado para com a educação está consagrada no artigo $2^{\circ}$ da Lei das Diretrizes e Bases da Educação Nacional:

Art. $2^{\circ}$ : a educação, dever da família e do Estado, inspirada nos princípios da liberdade e nos ideais de solidariedade humana, tem por finalidade o pleno desenvolvimento do educando, seu preparo para o exercício da cidadania e sua qualificação para o trabalho.

É fato que crianças e jovens comecem a gostar mais da escola, valorizar o processo ensino/aprendizagem e familiarizarem-se com os professores e colegas quando a família demonstra apreço pela escola e valoriza a prática docente como parte essencial da formação dos filhos. Entretanto, não se pode afirmar que os papéis da escola e da família na educação são equivalentes, já que assumem diferentes funções: enquanto cabe à escola a missão de ensinar as múltiplas leituras do mundo, cabe à família ensinar aos filhos os princípios fundamentais da conduta ética, da convivência pacífica e do contrato social. Mas tanto a família quanto a escola trabalham para a formação integral e para o exercício da cidadania.

Por pequena que seja em comparação com tudo o que há por fazer na escola a contribuição que os pais podem dar para o processo pedagógico escolar precisa ser levada em conta para evitar o risco de se ignorar algo que é imprescindível para o bom desempenho dos alunos.12)

Na prática, a participação da família na vida escolar dos filhos é de fundamental importância, principalmente quando as condições socioeconômicas não são boas. A política da reprovação ainda mais agrava o quadro da exclusão e contribui para as estatísticas do fracasso escolar, pois quando um aluno é reprovado, geralmente é qualificado como incapacitado e isso afeta diretamente sua autoestima. Estudos dão conta de que a reprovação não contribui para melhor aprendizagem no ano seguinte. Deste modo, a repetência não é sinônimo de melhoria na aprendizagem e, menos ainda, garantia de melhor desempenho nos anos seguintes. (13)

A realidade da educação mudou bastante nas últimas décadas, entre outras razões, devido à necessidade que têm os pais de saírem de casa em busca de sustento para a família. Neste sentido, a vida escolar dos filhos acaba ficando em segundo plano, pois, para muitos

Outubro, 2016:2(Edição Especial):14-27. 
pais, não participar acaba sendo mais interessante, uma vez que têm outras atividades que não podem deixar de assumir. Logo, resta à escola decidir o que fazer com as crianças e jovens que não se adaptam ao seu ambiente. A família transfere a responsabilidade para a escola e mantém-se alheia aos problemas que acontecem na aprendizagem. (13)

O distanciamento da família em relação à escola é lamentável, especialmente quando se considera que a disciplina na escola em geral reflete a maneira como o filho comporta-se em casa.

A família pode ajudar a disciplina na escola através de algumas práticas, readquirindo a prática do diálogo; ser capaz de impor limites e desligar a televisão, valorizar a escola e o estudo; superar a visão da escola como "mal necessário" para a ascensão social, não sufocando a curiosidade da criança, estimulando o gosto pelo conhecimento. Acompanhar sempre a vida escolar e não apenas quando o filho tem "nota vermelha".(13)

A parceria que deve estabelecer-se entre a escola e a família passa necessariamente pelo contato que o professor precisa manter diretamente com os pais, pois nem sempre a direção da escola e os especialistas estão preparados para responder às dúvidas da família sobre as dificuldades dos filhos e desses sobres as suas limitações.

É preciso reconhecer que a família, independente do modelo como se apresente, pode ser um espaço de afetividade e de segurança; mas também de medos, incertezas, rejeições, preconceitos e até de violência. Pais e professores devem ser parceiros no diálogo sobre a educação das crianças e jovens. Dialogar, perguntar, ousar respostas, tentar compreender as dificuldades apresentadas pelo ser em desenvolvimento. É preciso dialogar, com mediação do professor, que deve ser visto como parceiro no processo educacional. (14)

O fracasso escolar, portanto, não pode ser dimensionado apenas pelo insucesso na aprendizagem, não raro mensurado por meio de notas, mas deve ser levado em conta todo um universo de fatos, acontecimentos e relações que perpassam toda a vida prévia do aluno: as relações familiares, o meio mais ou menos culto em que vive, a apropriação e instrumentos de aprendizagem e o modo pelo qual se dá a prática do ensino/aprendizagem na escola.

A atuação do psicólogo no ambiente escolar dependerá muito do conhecimento holístico desse profissional sobre a realidade do aluno e sobre todos os elementos que desencadeiam o fracasso escolar. Assim, para que o trabalho alcance seus objetivos no espaço escolar há que se levar em conta que o profissional da psicologia não é mais meramente um avaliador. É um profissional das ciências humanas que se enquadra na área da saúde, porque não tem como haver saúde sem humanização. Faz-se necessário ao psicólogo ter uma visão mais abrangente da realidade social, de maneira a compreender fenômenos sociais como a desigualdade. (15)

Outubro, 2016:2(Edição Especial):14-27. 
Seria muito cômodo colocar a culpa apenas na família ou apenas na escola, quando, na realidade, existe todo um sistema de coisas que condicionam o sucesso ou o fracasso escolar. Basta lembrar que muito pouco tem sido feito para reverter o quadro do fracasso escolar. Além do que, há sérios indícios de que também pode haver problemas nas escolas e no sistema educacional. (13) Trata-se, então, de uma questão muito mais ampla, que precisa ser analisada à luz das questões de cunho social, econômico e educacionais de maior relevância na realidade do aluno e da família. É necessário que se leve em conta que muito além dos limites dos muros escolares existe um amplo universo no qual o aluno está inserido e as lutas e embates pela aceitação e igualdade no mundo externo apresentam reflexos diretos na aprendizagem, pois é compreensível que em vários momentos o sofrimento psíquico tem sua base no fato do indivíduo não conseguir suportar a frustração de estar fora dos padrões ideais impostos pela cultura, com a visibilidade que esses fatores de desigualdades são maléficos para a subjetividade do indivíduo que as sofrem, percebe-se que o ser humano tem uma necessidade de igualdade, de relações satisfatórias e éticas. (15)

\section{RESULTADOS E DISCUSSÃO}

O trabalho do psicólogo no ambiente escolar passa necessariamente pela análise da intervenção da família na aprendizagem, pois o fato da relação deficitária escola/família ser apenas parte das causas do fracasso escolar, não serve para isentar a família de seu importante e múltiplo papel de sustentar, guardar e educar os filhos.

Contudo, a atuação do psicólogo na educação, dentro ou fora dos muros escolares, é bem mais ampla, especialmente nos tempos atuais, em que os problemas de ordem psicológica com reflexo na aprendizagem tendem a aumentar.

As possibilidades de atuação do psicólogo na instituição escolar constituem, ainda, um tema de reflexão e de debate entre esses próprios profissionais [...]. O debate e os questionamentos se expressam, também, em diferentes instâncias do sistema educativo e deles participam, em diferentes graus, gestores, pedagogos e outros especialistas no campo da educação. ${ }^{(16)}$

No que se refere especificamente ao ambiente escolar, a atuação do psicólogo é essencial para que determinados problemas de aprendizagem sejam devidamente analisados, descobertas as origens, diagnosticados e solucionados. Na verdade, o trabalho do psicólogo, neste sentido, não se restringe apenas ao trato com os alunos que apresentem limitações cognitivas.

Outubro, 2016:2(Edição Especial):14-27. 
Um olhar atento ao desenvolvimento integral dos estudantes permite ao psicólogo estruturar um trabalho de orientação a alunos e pais, seja de forma individualizada, seja de forma grupal, que contribua para o desenvolvimento almejado. A coordenação de grupos de orientação a pais, em função de suas demandas no que diz respeito aos aspectos psicológicos do desenvolvimento e da educação dos filhos, tem representado uma das vias mais significativas do trabalho do psicólogo nesse sentido mais amplo. ${ }^{(16)}$

Além de estar atento à realidade social e familiar do aluno enquanto paciente, o psicólogo deve ainda atentar para a realidade da escola, ciente de que, muitas vezes, uma parte significativa dos problemas de aprendizagem decorre da metodologia adotada, do tipo de clientela da escola, dos profissionais que a integram e até mesmo do espaço físico pouco propício à prática docente.

Um trabalho eficiente nessa linha teria que partir de uma análise da instituição, levando em conta o meio social no qual se encontra e o tipo de clientela que atende, bem como os vários grupos que a compõem, sua hierarquização, suas relações de poder, passando pela análise da filosofia específica que a norteia, e chegando até a política educacional mais ampla. ${ }^{(17)}$

Em sua atuação, deve considerar não apenas os aspectos individuais dos alunos, mas também aspectos do corpo docente, do currículo, projetos políticos pedagógicos, métodos de ensino, políticas educacionais e demais características institucionais. ${ }^{(18)}$

Em síntese, em cada caso específico o psicólogo terá que definir de que modo e com quais instrumentos dar-se-á sua atuação, ciente de suas múltiplas funções junto aos professores, especialistas, pais e alunos. De qualquer modo, terá que levar em conta a realidade de um mundo em transformação, dentro do qual imperam a inversão de valores e a progressiva perda de autoridade dos pais e dos professores, especialmente em razão do predomínio da influência da Internet e do fracasso da educação sistematizada e tradicional.

Os resultados da pesquisa poderão servir de base para pesquisas mais avançadas com o objetivo de solidificar a atuação dos profissionais da psicologia pelo fortalecimento da educação no Brasil, mormente em uma época em que a família se encontra desestruturada e os problemas sociais avolumam-se, refletindo diretamente na maneira como as crianças e adolescentes apropriam-se das informações e aprendem as regras fundamentais de conduta.

\section{CONCLUSÃO}

Outubro, 2016:2(Edição Especial):14-27. 
Embora a atuação do psicólogo no ambiente escolar apresente múltiplas vertentes o seu objetivo é basicamente o mesmo: contribuir para que o processo ensino/aprendizagem alcance seu objetivo, qual seja, a aprendizagem do aluno, para tanto, precisa valer-se de seus conhecimentos sobre a natureza do pensamento e do comportamento humano para que possa propor soluções para os possíveis problemas.

Essencialmente, o psicólogo escolar é um profissional que utiliza os conhecimentos produzidos sobre o funcionamento psicológico humano para colaborar com os processos de aprendizagem e desenvolvimento que têm lugar no contexto escolar, tendo em conta a complexa teia de elementos e dimensões que nos caracterizam e que, de alguma forma, nos determinam. ${ }^{(16)}$

É muito comum que a escola apresente demanda para uma atuação curativa do psicólogo, especialmente porque quase sempre os problemas são percebidos muito tardiamente, quando já se notam suas consequências negativas na aprendizagem. Entretanto, a atuação do psicólogo no sentido de prevenir o surgimento dos problemas na escola apresenta-se como a mais indicada, uma vez que reduz custos e produz efeitos mais duradouros.

Deste modo, o trabalho do psicólogo dentro da escola na linha preventiva, contemplando o atendimento aos alunos, pais e professores é indispensável, dada a complexidade dos aspectos psicológicos que pressupõem um conjunto de relacionamentos e comportamentos que estão envolvidos no processo. ${ }^{(19)}$

Por tratar-se de uma vertente relativamente nova, a psicologia escolar ainda carece de delimitações, uma vez que se verifica, na atualidade, uma miscigenação entre os papéis do psicólogo, do pedagogo e do psicólogo escolar, o que, na prática, exige uma reflexão crítica e contextualizada. ${ }^{(20)}$

O psicólogo escolar, hoje, busca a reafirmação de sua identidade profissional, especialmente pela compreensão social de sua função enfrentando dois desafios: primeiramente a luta de poder no campo escolar, que envolve necessariamente a afirmação da identidade e a limitação de seu papel. Depois, a necessidade de atuação preventiva, que abrange a escola e a família, distanciando-se da atuação clínica (curativa) para fixar-se nos elementos que podem desencadear o fracasso escolar. ${ }^{(21)}$

Outubro, 2016:2(Edição Especial):14-27. 
Contudo, além de ser pouco comum a presença de psicólogos no ambiente escolar, predomina ainda uma ideia segundo a qual o profissional da psicologia teria uma solução pronta e imediata para os problemas de aprendizagem.

Nas instituições educativas, tem-se que ainda é rara a presença do psicólogo, e quando ele está presente, a comunidade escolar costuma criar expectativas de uma atuação voltada para resolução de problemas emergenciais, relativos à aprendizagem, comportamento e outros. ${ }^{(22)}$

O mais importante é que se procure superar o enfoque curativo da atuação do psicólogo na escola, criando uma perspectiva desenvolvimentista, mais voltada nas competências do que nas dificuldades de aprendizagem. Neste sentido, caberia ao psicólogo dentro da escola contribuir para a promoção do desenvolvimento global dos alunos, implementando, inclusive, a orientação profissional. (23)

Evidentemente a atuação remediativa do psicólogo na escola, posto que seja a mais desejada, é também importante. Contudo, ela somente tem sentido quando aliada ao trabalho preventivo. Uma atuação em Psicologia Escolar que busque abranger toda a instituição educacional e que se comprometa com um trabalho de caráter mais desenvolvimentista do que remediativo não pode prescindir de ter como foco de intervenção as relações interpessoais que se processam no cotidiano institucional. (22)

\section{REFERÊNCIAS}

1. Saraiva I. S. Aprendendo com alunos: uma experiência dialógica no curso de Pedagogia nos anos iniciais. Passo Fundo. RS: UPF Editora; 2004.

2. Souza M. P., Checchia A. C. Queixa escolar e atuação profissional: apontamentos para a formação do psicólogo. São Paulo: Casa do Psicólogo; 2001.

3. Meira M. E. Psicologia Escolar: Teorias Críticas. São Paulo: Casa do Psicólogo; 2003. Construindo uma concepção crítica de Psicologia Escolar: contribuições da Pedagogia Histórico-Critica e da Psicologia Sócio-Histórica; p. 13-77.

4. Andrada E. Novos paradigmas na prática do psicólogo escolar. Psicologia: Reflexão e Crítica [Internet]. Santa Catarina; s.d. [2016 maio 08].

http://www.scielo.br/pdf/prc/v18n2/27470.pdf

Outubro, 2016:2(Edição Especial):14-27. 
5. Patto Maria Helena S. A produção do fracasso escolar. São Paulo: T.A. Queiroz; 1990.

6. Brasil Lei das Diretrizes e Bases da Educação Nacional - Lei 9394/96. Presidência da República. Casa Civil. Subchefia para Assuntos Jurídicos [Internet]. Brasília; s. d. [2016 mar. 18]. http://www.planalto.gov.br/ccivil_03/leis/L9394.htm

7. Hoffmann Jussara. Avaliação mediadora: uma prática em construção da pré-escola à universidade. Scribd. [Internet]. Porto Alegre; s. d. [2016 mar. 18]. https://pt.scribd.com/doc/141241103/AVALIACAO-MEDIADORA-UMA-PRATICA-EMCONSTRUCAO-DA-PRE-ESCOLA-A-UNIVERSIDADE

8. Silva Raimundo P. A escola enquanto espaço de construção do conhecimento. São Paulo: Revista Espaço Acadêmico; 2012

9. Glória Dilia M. A prática da não retenção escolar na narrativa de professores, alunos e familiares [dissertação]. Belo Horizonte: Pontifícia Universidade Católica de Minas Gerais;2002

10. Salomon Maria L. Alguns mecanismos de produção de percursos escolares acidentados nos meios sociais favorecidos. [dissertação]. Belo Horizonte: Pontifícia Universidade Católica de Minas Gerais; 2001.

11. Kaloustian Sílvio M. Família brasileira: a base de tudo. São Paulo: Cortez; 1998.

12. Paro Vitor H. Gestão democrática. Rio de Janeiro: DP \& A; 2001. Administração escolar e qualidade de ensino: o que os pais ou responsáveis têm a ver com isso? ; p. 57-72.

13. Lacerda Chrislaine K. Repetência e Fracasso Escolar. Escavador [Internet]. Jussara. Paraná; s. d. [2016 abr. 02]. http://www.gestaoescolar.diaadia.pr.gov.br/arquivos/File/producoes_pde/artigo_chisla ine_keile_fernandes_ruiz_lacerda.pdf

14. Fiale Luciana A. Fracasso Escolar: Família, escola e a contribuição da Psicopedagogia. UNIFAI - Centro Universitário Assunção [Internet]. São Paulo; s. d. 
[2015 dez. 08].

http://www.unifai.edu.br/publicacoes/artigos_cientificos/alunos/pos_graduacao/18.pdf

15. Borges M A R, Amaral A F . A desigualdade social e suas influências na subjetividade contemporânea. Psicologia e Saúde em Debate [Internet]. 2015 [2016 jun. 29]; 1(2):3-19. https://psicodebate.files.wordpress.com/2015/08/1-borges-eamaral-2015.pdf.

16. Martinez Albertina M. O que pode fazer o psicólogo na escola? Em Aberto. [Internet]. Brasília; s. d. [2016 mar. 18]. http://leticiawfrancomartins.pbworks.com/w/file/fetch/98938496/Texto\%201.pdf

17. Andaló Carmem Silvia A. O papel do psicólogo escolar. Psicologia: Ciência e Profissão [Internet]. Brasília; s. d. [2106 mar. 18].

http://www.scielo.br/scielo.php?script=sci_arttext\&pid=S1414-98931984000100009

18. Sargiani R. O que faz um psicólogo na escola? Psicologia: Ciência e Profissão [Internet]. Brasília; s. d. [atualizado s. d; 2016 abr. 02].

http://www.psicologiaexplica.com.br

19. Santos Evanice, Bezerra Maria do Socorro P., Tadeuci Marilsa de S. R. Educação: a importância do psicólogo no contexto escolar. XIV Encontro Latino-americano de iniciação científica. Universidade de Taubaté [Internet]. Taubaté; s. d. [2016 jan. 10]. http://www.inicepg.univap.br/cd/INIC_2010/anais/arquivos/0071_0081_01.pdf

20. Jobim e Souza S. Pedagogia ao pé da letra. Teresópolis: ANPEPP; 1996. O psicólogo na educação: identidade e (trans)formação; p. 37-45.

21. Valle Luiza Elena L. Psicologia escolar: um duplo desafio. Psicologia: Ciência e Profissão [Internet]. Brasília; s. d. [2016 maio 15].

http://www.scielo.br/scielo.php?script=sci_arttext\&pid=S1414-98932003000100004

22. Carvalho Tatiana O, Araújo Claysi M. Marinho. Psicologia Escolar e Orientação Profissional: fortalecendo as convergências. Periódicos Eletrônicos em Psicologia [Internet]. São Paulo; s. d. [2016 maio 15].

http://pepsic.bvsalud.org/scielo.php?script=sci_arttext\&pid=S167933902010000200007

Outubro, 2016:2(Edição Especial):14-27. 
23. Taveira Maria do C. Psicologia escolar: Uma proposta científico-pedagógica.

Coimbra, Portugal: Quarteto; 2005. 